\title{
O DETERMINANTE DEMONSTRATIVO EM SINTAGMAS NOMINAIS
}

\author{
GRAZIELA ZAMPONI* \\ UNICAMP/FAENQUIL/FATEA
}

\begin{abstract}
In this paper we start a reflection about demonstrative noun phrases. From the concept of memorial deixis, we infer the presence of an associated "subjectivity" in the use of demonstrative determiners, through which the speaker calls the addressee's attention to an object, therefore giving a discursive dimension to this type of determiner.
\end{abstract}

No presente trabalho focalizamos a questão do sintagma nominal demonstrativo ${ }^{1}$ (SND), tema que vem ocupando cada vez mais a atenção de estudiosos. Não temos a pretensão de formular uma hipótese sobre o princípio de funcionamento do demonstrativo que se aplicaria a todos os empregos desse determinante e seu uso em português, nem traçar uma diferenciação entre ele e o definido, que é aqui abordado de forma episódica e a título de comparação, mas apenas apresentar algumas considerações que servem de ponto de partida para uma reflexão sobre o tema. Para iniciar essa reflexão, tomemos como exemplo (1).

\section{(1) Cestas básicas}

Será que enfim resolveram acabar com a síndrome 'vítima-coitado' que assola a mentalidade deste país? Essa maneira de pensar é uma das principais causas da indigência social em que vivemos. Acabar com a entrega de cestas básicas gratuitas demonstra que estamos começando a tomar consciência de que para resolver os problemas sociais, temos de iniciar pela promoção humana, recuperando a auto-estima e a auto-valorização de cada cidadão.

Claro que há que se buscar alternativas a esse corte, mas que sejam alternativas inteligentes, que proporcionem a essas pessoas a possibilidade de participar efetivamente das relações de consumo inerentes a qualquer sociedade. (Santiago Torrente Perez, Folha de S.Paulo, 29/11/00 - A-3 )

\footnotetext{
* A autora é doutoranda em Lingüística na UNICAMP, sob a orientação da Prof ${ }^{\mathrm{a}} \operatorname{Dr}^{\mathrm{a}}$ Ingedore V. Koch.

${ }^{1}$ Abordamos aqui apenas os casos do demonstrativo adjetivo.
} 
Interessa-nos em (1) a ocorrência de dois $\mathrm{SND}^{2}$ : "esse corte" e "essas pessoas". No primeiro caso, temos uma nominalização ${ }^{3}$, cuja informação-suporte é "acabar com a entrega de cestas básicas gratuitas", processo que não exige do leitor uma estratégia inferencial mais complexa. Apothéloz e Chanet (1997: 165) inclusive afirmam que, de modo geral, os SN utilizados nas nominalizações manifestam uma clara propensão a uma determinação demonstrativa. E acrescentam que praticamente é possível sempre substituir uma nominalização definida por um demonstrativo, mas não o contrário. Mas, fazendo o percurso inverso, podemos perfeitamente substituir "esse corte" por "o corte". Isso nos leva a reconhecer que em alguns contextos as duas formas de determinante se encontram em variação livre.

Caso mais interessante constitui o SND "essas pessoas". De que pessoas se trata? O determinante demonstrativo aponta para que antecedente? O uso desse SN pode ser considerado anafórico? Se buscarmos no contexto prévio, veremos que não há um antecedente claro para a descrição demonstrativa. No entanto, a expressão em questão não oferece qualquer problema interpretativo. Mas, se retirarmos o primeiro parágrafo, fica evidente que se cria um problema de interpretação, pois é ele que estabelece o contexto englobante para o emprego do SND: trata-se das pessoas que não mais receberão cestas básicas, actante implícito de "acabar com a entrega de cestas básicas." Poderíamos considerar esse SN como um dos casos das anáforas indiretas, que constituem "relações referenciais produzidas por sintagmas nominais definidos, verbos, adjetivos, pronomes ou até mesmo orações que não retomam pontualmente ou explicitamente elementos anteriormente (ou posteriormente) presentes na superfície do texto, mas ancoram em elementos do discurso, da situação cognitiva ou outros para ativar ou introduzir um referente novo como se fosse dado. Mesmo inexistindo um vínculo de retomada direta entre uma AI e um cotexto antecedente ou posterior, persiste um vínculo coerente na continuidade temática que não compromete a compreensão." (Marcuschi, Luiz A., "O barco textual e suas âncoras", texto não publicado)

Se substituirmos o demonstrativo pelo definido, teremos "as pessoas" ocorrendo aqui um caso de uso genérico do definido. Essa substituição alteraria o conjunto em que se deve identificar o referente: tratar-se-ia de todas as pessoas e não só aquelas que deveriam receber cestas básicas. Aqui o determinante demonstrativo e definido não se encontram em variação livre.

Em vários trabalhos, a abordagem do demonstrativo limita-se à oposição dêixisanáfora, concebida quanto à localização do referente, respectivamente, na situação de enunciação e no contexto lingüístico. Mas Gary-Prieur e Noailly (1996) apontam um

\footnotetext{
${ }^{2}$ Não abordaremos aqui os SND "este país" (emprego dêitico) e "essa maneira de pensar"., SND constituído de det. + nome + verbo. Apothéloz (1995: 287) aponta que expressões como "esse tipo de...", "essa espécie de... "esse gênero de..." - seguidos de substantivos - são operadores que permitem construir objetos genéricos a partir de uma referência específica ou, numa outra interpretação, são expressões que problematizam a categorização lexical do objeto.

${ }^{3}$ A nominalização constitui uma operação discursiva que consiste em referir, por meio de um sintagma nominal, a um processo ou um estado expresso anteriormente por uma proposição. Ao lexema utilizado como núcleo da expressão que marca essa operação denomina-se substantivo predicativo; à proposição a que o substantivo-predicativo remete denomina-se informação-suporte. (cf. Apothéloz e Chanet, 1997).
} 
uso insólito do demonstrativo em textos literários, caso em que o SND não é usado nem deiticamente (mesmo porque a situação de enunciação de um texto literário se reveste de características muito particulares, estatuto que não cabe discutir aqui) nem anaforicamente (porque não há antecedente explícito). Isso significa que não há nem a presença do denotatum no campo perceptivo dos interlocutores (emprego dêitico in praesentia), nem uma menção do referente no contexto verbal (emprego dito anafórico). No uso insólito do demonstrativo, ocorre uma imposição cognitiva, psicológica ou memorial do referente nas representações mentais do locutor (situação descrita sob o nome de dêixis in absentia ou dêixis memorial, entre outros termos usados na literatura). Podemos citar como exemplo "extremo", por se tratar de um texto poético, o poema Retrato, de Cecília Meireles:

(2) Eu não tinha este rosto de hoje,

Assim calmo, assim triste, assim magro

Nem estes olhos tão vazios

Nem o lábio amargo.

Eu não tinha estas mãos sem força

Tão paradas e frias e mortas

Eu não tinha este coração

Que nem se mostra.

Eu não dei por esta mudança

Tão simples, tão certa, tão fácil.

Em que espelho ficou perdida

A minha face?

Os SND "este rosto de hoje", "estes olhos tão vazios", "estas mãos sem força” e "este coração / que nem se mostra" não exigem uma busca da referência no contexto lingüístico ou na situação extra-lingüística. O leitor não é convidado a procurar, fora da descrição demonstrativa, um referente com o qual saturar de qualquer forma o designador, mas esse determinante não está despido inteiramente de uma função indexical: ele leva o leitor a compreender que se trata de entidades com as quais o locutor tem uma relação experiencial, dentro do que Gary-Prieur e Noailly (1996: 118) chamam de "memória do locutor-autor" um interlocutor: o locutor-autor é, nessas situações de "discurso interno", seu próprio interlocutor ${ }^{5}$. Dito de outra forma, o locutor não tem necessidade de fornecer nenhum

\footnotetext{
${ }^{4}$ Gary-Prieur \& Noailly (1996) afirmam que, embora os lingüistas considerem hoje que o demonstrativo serve para apresentar um objeto "saliente", isto é, presente na memória imediata do destinatário, a "saliência" do objeto introduzido pelo demonstrativo em seu uso insólito está na memória do "locutorautor", sendo um objeto localizado em relação ao universo do sujeito da enunciação.

5 Aqui o demonstrativo apresenta duas funções opostas: uma função conativa, por meio da qual o autor convida o leitor a partilhar seu universo, e uma função de distanciamento, que o autor usa para remeter o leitor ao exterior do universo de seu texto. A primeira provém do esforço de interpretação requerido por esses
} 
apoio externo a seu próprio universo de enunciação; a identificação do referente se faz inteiramente no seu universo mental, ou se se quer, em seu campo memorial (isso não é surpreendente em textos escritos em primeira pessoa). Já o SND "esta mudança" constitui um caso de nominalização, designando as alterações por que passou o eulírico, marcadas pelo tempo verbal (pretérito imperfeito do indicativo) e pelo modificador "de hoje".

Quanto aos três usos do demonstrativo (dêitico, anafórico e dêitico memorial), Béguelin (1998) distingue a perspectiva do locutor e alocutário. Na perspectiva do alocutário, os empregos situacionais e anafóricos são os mais normais porque mais fáceis de tratar, na medida em que o referente a se identificar se encontra já validado na imagem da memória discursiva ${ }^{6}$ que se forma desse alocutário, por meio dos conhecimentos que ele tem do contexto em sentido amplo. No momento da ocorrência do SND, M inclui seja a informação de origem perceptual associada ao denotatum, seja informação construída por via verbal. Os pressupostos ${ }^{7}$ associados à forma lingüística esse $N$ são assim verificados pelo estado de $\mathrm{M}$, e a competência inferencial do intérprete é apenas modestamente solicitada.

Do ponto de vista do locutor, ao contrário, a dêixis memorial tem o mérito de ser pouco restritiva. De maneira egocêntrica, o locutor poupa-se de adaptar estritamente a forma de seu discurso ao estado presumido de conhecimentos partilhados, utilizando o SND "unilateralmente"; cabe ao alocutário acomodar M a posteriori. Aqui entra em jogo um contrato de comunicação fundamentado não sobre a antecipação de dificuldades interpretativas, mas sobre o apelo à cooperação do alocutário, que deve "verificar" por si mesmo os pressupostos inerentes ao SND.

Como são mais rotineiros e menos suscetíveis de resultar em um incidente interpretativo, os usos situacionais e anafóricos do SND acabam passando por modelares. De um modo um pouco provocador, Béguelin (1998) afirma que esses dois usos do SND constituem casos particulares da dêixis memorial, em que um referente, cognitivamente imposto pelo locutor e "mostrado" como tal pelo SND, se encontra validado em M seja por meio do contexto verbal, seja pelas evidências ligadas à situação de enunciação. Neste caso, as entradas perceptivas e contextuais não fazem senão confirmar a validade de referentes inferidos.

A partir daí, podemos inferir uma "subjetividade" associada ao demonstrativo, que pode ser vista na própria definição gramatical desse determinante. Em Bechara (2000: 167), por exemplo, encontramos: [pronomes demonstrativos] "são os que indicam a

demonstrativos, que aproximam leitor e autor e a segunda resulta da recusa de dar ao leitor os meios necessários para identificar o referente. (Gary-Prieur \& Noailly, 1996: 119-20)

${ }^{6}$ A memória discursiva (= M) constitui o conjunto evolutivo de conhecimentos oficialmente partilhados pelos interlocutores, sendo alimentada pelas enunciações, pelos elementos percebidos associados à situação de enunciação e pelas inferências que deles decorrem.

${ }^{7}$ O SND, assim como o definido, constitui caso de designação, pois remete a um objeto; daí a eles estar associada a pressuposição existencial referencial. Mas a pressuposição de existência do definido e do demonstrativo não é da mesma ordem. No primeiro caso, o emprego referencial resulta do sentido pressuposicional de unicidade de existência veiculado pelo artigo; no segundo, a pressuposição de existência do referente não é senão conseqüência: o emprego do demonstrativo veicula por si mesmo uma pressuposição existencial. (cf. Kleiber, 1984). O ato de mostrar engaja a pessoa que realiza esse ato a crer na existência daquilo que ela mostra. 
posição dos seres em relação às três pessoas do discurso". Existe um antropomorfismo no verbo "indicar", que dota o demonstrativo de um poder gestual. Mas, na verdade, quem indica? Podemos responder que se o demonstrativo indica, essa indicação é dada pelo locutor e não pelo próprio demonstrativo. Isso se confirma quando o autor (p. 189), abordando os usos desse pronome, afirma no item demonstrativos referidos a nossas próprias palavras: No discurso, quando o falante deseja fazer menção ao que ele acabou de narrar (anáfora) ou ao que vai narrar (catáfora), emprega este (e flexões). Ele cita o seguinte exemplo de Camilo Castelo Branco: "Entrou Camilo na sala um pouco mais tarde que o costume, porque fora vestir-se de calça mas cordata em cor e feitio. Não me acoimem de arquivista de insignificâncias. Este pormenor (isto é: o pormenor a que fiz referência) das calças prende mui intimamente com o cataclismo que passa no coração de Barbuda". A interpolação do comentário do gramático, entre parênteses, mostra a subjetividade que acompanha o determinante demonstrativo: tratase do pormenor a que o eu (= o locutor) se referiu.

Assim, esse $N=o$ N que eu mostro, o $N$ de que eu falo. Fica claro que o "gesto" associado ao demonstrativo é do locutor. Mas Gary-Prieur (1998) aponta ainda que, além dessa face do demonstrativo, há outra orientada para o destinatário do enunciado. Se se retorna à imagem do gesto, é preciso ver que o demonstrativo coloca em jogo três instâncias: aquele que mostra, o que é mostrado e aquele a quem se mostra. Esse permite apresentar um objeto como sendo ligado às pessoas do discurso, o que lhe dá uma dimensão discursiva. A autora propõe a seguinte definição para o demonstrativo:

Esse $N=$ um x que é um $\mathrm{N}^{8}$ e sobre o qual eu chama atenção de tu.

Essa definição mostra que o referente do demonstrativo, classificado como N, é identificado para o locutor e não impõe nenhuma condição de identificação prévia para o alocutário. Isso pode explicar a contento o emprego insólito desse determinante. E talvez aí repouse a dificuldade para a resolução do demonstrativo em relação aos outros determinantes (indefinido e definido): a instrução semântica dada pelo demonstrativo é precisamente colocar o referente do $\mathrm{SN}$ introduzido em relação com o par eu/tu constitutivo do discurso.

$\mathrm{O}$ fato de o demonstrativo designar um objeto conhecido do locutor e não necessariamente conhecido do alocutário permite levar à hipótese de que essa forma tem duas faces superpostas: sempre remete a alguma coisa conhecida e apresenta alguma coisa como nova. (De Mulder, 1998). O demonstrativo traz o novo seja porque introduz um referente no discurso, seja porque assinala uma mudança de estatuto discursivo (uma mudança de foco), seja porque situa um referente em um novo universo de consciência. Assim, o SND não serve para marcar a continuidade pura e simples de uma menção anterior, mas ele leva sempre o novo no sentido de marcar seja a saliência do referente, seja uma modificação do estatuto temático.

Entre as funções textuais do demonstrativo, Apothéloz (1995) aponta uma função em que esse determinante chama a atenção sobre um objeto entre outros objetos localmente salientes ou designa um objeto que deixou de ser o centro do campo de

\footnotetext{
${ }^{8}$ Corblin (1987: 209) afirma que o grupo nominal esse $N$ classifica seu designatum como X.
} 
atenção por outro objeto promovido a esse estatuto. Mas como já pontuamos neste trabalho, essa saliência, ou o seu correlato psicológico, a atenção, diz respeito a um objeto localizado em relação ao universo do sujeito da enunciação.

A título de ilustração, vejamos dois textos de Gilberto Dimenstein, publicados, respectivamente, no caderno A e C da edição da Folha de S.Paulo de 29/11/2000.

(3) Ao analisar os resultados do sistema Nacional de Educação do MEC, o ministro Paulo Renato Souza (Educação) afirmou que "a escola está cada vez mais chata, e o aluno cada vez mais dispersivo ou indisciplinado".

A pesquisa deste ano mostrou queda de aproveitamento nas escolas particulares.

Para Paulo Renato, esse "efeito chatice" é provocado por duas razões centrais: a falta de reciclagem das escolas e a grande oferta de conhecimento fora da sala de aula, principalmente na Internet.

(4) "A escola está cada vez mais chata, e o aluno cada vez mais dispersivo ou indisciplinado", disse ontem o ministro da Educação, Paulo Renato Souza, ao analisar os resultados do Saeb (Sistema Nacional de Avaliação da Educação Básica do MEC), que mostram queda de aproveitamento nas escolas particulares, conforme revelou a Folha, na edição de ontem.

O "efeito chatice" é provocado porque, de um lado, a escola não se reciclou, o professor interage pouco com os alunos, os conteúdos devem ser decorados, as matérias estão distantes da realidade.

Nesses textos, chama-nos a atenção o uso do demonstrativo e do definido no SN "efeito chatice". Nos dois casos, trata-se de uma denominação reportada, fator que, segundo Apothéloz e Chanet (1997), favoreceria o uso do demonstrativo. Não se trata, é óbvio, de uma coerção e o uso do definido atesta isso. Mas o efeito é diferente: na designação com o demonstrativo, o locutor torna saliente o objeto, entre outros que se encontram na memória discursiva do alocutário (leitor), como "os resultados do sistema Nacional de Educação do MEC", "a pesquisa deste ano", "queda de aproveitamento nas escolas particulares". Com essa estratégia, o locutor chama a atenção do alocutário para esse objeto; com o definido, o que está ausente é justamente essa saliência. Em outras palavras, no caso do definido, o locutor presume que o referente ainda está no foco de atenção do alocutário (cf. Cornish, 1999). Isso explica a mudança de determinante, pois se considerarmos que (3) está na primeira página e (4) no interior do jornal, podemos pensar que o locutor supõe que o alocutário já tem em foco o referente pretendido quando usa o definido, pois presume que o leitor já tenha tido contato com o texto em que ele torna saliente o referente pelo uso do SND. 


\section{À guisa de conclusão (provisória)}

a) O demonstrativo, em todos os seus empregos, tem um caráter indexical: trata-se de apresentar o referente como "aquele que eu mostro, aquele de que eu falo";

b) Esse caráter indexical carrega em si uma subjetividade: o apontamento é da responsabilidade do locutor;

c) O demonstrativo apresenta um referente como novo (para o alocutário) - no sentido apontado mais acima - e velho (para o locutor).

Resta ainda precisar muitos pontos, como por exemplo, a função textual do SND, a possível restrição de sua função sintática, a função dos modificadores que porventura o integrem, a sua relação com gêneros de discurso, entre outros. Mas isso é motivo para uma pesquisa mais ampla.

\section{$\overline{\text { REFERENCIAS }}$}

APOTHÉLOZ, D. (1995). Rôle et fonctionnement de l'anaphore dans la dynamique textuelle. Genève: Droz.

APOTHÉLOZ, D., CHANET, C. (1997). Défini et démonstratif dans les nominalisations. In DE MULDER, Walter e Carl Vetters (eds.) Relations anaphoriques et (in)cohérence. Amsterdam: Rodopi. p. 159-86.

BECHARA, E. (2000). Moderna Gramática Portuguesa. 37.ed. revista e ampliada. Lucerna: Rio de Janeiro.

BÉGUELIN, M-J. (1998). L'usage des SN démonstratifs dans les Fables de La Fontaine. In Langue Française. Paris: Larousse, n. 120, p. 95-109.

CORBLIN, F. (1987). Indéfini, défini et démonstratif. Genève: Droz.

CORNISH, F. (1999). Anaphora, Discourse, and Understanding: Evidence from English and French. New York: Oxford University Press.

DE MULDER, W. (1998). Du sens des démonstratifs à la construction d'univers. Langue Française. Paris: Larousse. n. 120, p. 21-32.

GARY-PRIEUR, M-N, NOAILLY, M. (1996). Demonstratifs insolites. Poétique. Seuil, n. 105, p. 111-21.

GARY-PRIEUR, M-N., LEONARD, M. (1998). Le démonstratif dans les textes et dans la langue. Langue Française. Paris: Larousse. n. 120, p. 5-20.

KLEIBER, G. (1984). Sur la sémantique des descriptions demonstratives. Lingvistica Investigationes. Amsterdam, p. 63-85.

MARCHUSCHI, L.A. Anáfora indireta: o barco textual e suas âncoras. (texto não publicado). 